\title{
Talking Techne: Techniques to Establish An Active Online Discussion Forum
}

\author{
Stephanie Maher Palenque | Meredith DeCosta
}

Discussion forums are critically important to the online classroom, as they virtually take the place of a classroom discussion

and become a stage on which active learning takes place. Active learning occurs when instructors practice certain tech-

niques in the discussion that are carefully and thoughtfully crafted and guided. The authors propose the term "techne" to

describe the specific tools and processes used by instructors who are mindful of this purposeful guidance. By implementing

these techne in asynchronous discussions, and revising as needed after close observation and student feedback, a unique and

productive active learning experience is shared by everyone in the online classroom. These techniques are generalizable to all

online courses, regardless of subject area.

In 1916, progressive education pioneer John Dewey argued that active learning helps students think critically about the world around them. Dewey (1916) contended that active learning occurs when there are opportunities in the classroom for students to freely explore concepts with the conscious guidance of a teacher. Active learning involves interacting and collaborating with peers, as well as sharing, testing, and trying out new ideas amongst peers (Dewey, 1916). One hundred years later, Dewey's theory is still widely accepted. Passive, receptive learning through rote activities and instructor-led lectures are not ideal techniques to foster student growth (Dewey, 1916). Active learning, on the contrary, encourages growth by tapping into the natural instincts of humans to be curious, inquisitive beings (Dewey, 1916). It is this instinct that successful instructors access to make critical connections between students and material.

\section{ACTIVE LEARNING IN THE ONLINE DISCUSSION FORUM}

Online learning is growing at a rapid pace. The number of students participating in online learning has increased: 6.7 million students are taking at least one online course and $86.6 \%$ of colleges and universities now offer online courses (Allen \& Seaman, 2013). The expansion of e-learning leads to the question: what might active learning look like in an online classroom? How might Dewey's vision of active learning come to fruition in an asynchronous learning environment?

In the online classroom, there is generally no opportunity for face-to-face collaboration with peers or instructors. Further, often learning management systems (LMS) do not offer an avenue for students to engage in demonstrably active learning tasks like role-play or debate. Arguably, active learning in the online classroom is most likely to take place in the discussion forums (Palenque \& DeCosta, 2014). Asynchronous discussions have the potential to extend and enhance instruction in the online classroom. Online discussions may allow for more in-depth and thoughtful learning than faceto-face settings (Hawkes, 2006). When consciously constructed by an instructor, online discussions play a key role in facilitating student learning and fostering dialogue, critical thinking, and reflective inquiry (Kayler \& Weller, 2007; Morris, Finnegan, $\&$ Sz-Shyan, 2005). Constructivist educators have long held that engaging students in meaningful, relevant activities improves learning (Dewey, 1916; Freire, 1970). The more active students are in the process, the more learning occurs. In the online environment, the discussion forum is a channel to active learning, as well as a useful critical thinking tool. The theoretical underpinning of this concept of learning via class discussion posits that students actively create their knowledge through interactions 
with peers (Bradley, Thom, Hayes \& Hay, 2008; Vygotsky, 1978). Through interactions with peers, knowledge is leveraged and scaffolded until students can complete tasks independently (Vygotsky, 1978). The discussion board is the stage on which the text will come to life for students, and the concepts they read will be analyzed, practiced, and manipulated through active discussion.

Although discussion forums have the potential to generate active learning opportunities, they are not easy to establish and manage. Instructors must engage students in critical discourse through engaging questions, focused discussion, and opportunities to test ideas and contribute to conversations (Garrison \& Cleveland-Innes, 2005). Further, they necessitate the knowledge and use of appropriate strategies to encourage student participation, including posed questions and scenarios that lead to active learning. There are no "one size fits all" guidelines for managing a successful online forum; however, a true active community of online learners is established when instructors balance their roles as leaders, information providers, and facilitators in order to foster active discussions within the online classroom (Mitchem et al., 2008; Ragan, n.d.).

In their critical roles as leaders, instructors must be present and active in discussions within the online classroom (Garrison, Anderson, \& Archer, 2000; Garrison \& Cleveland-Innes, 2005). According to Bliuc, Ellis, Goodyear, and Piggott's (2009) study, discussions (both online and face-to-face) with deep learning methods, such as integrating one's own ideas and thinking about larger perspectives, resulted in higher achievement than discussions approached with surface learning methods like posting without integrating opportunities for critical analysis, simply because these methods are a compulsory part of the course and not an opportunity to engage in metacognitive processing of ideas and concepts. A random approach by online instructors to posting in online forums may demonstrate to the students that the instructor is present, but it will not likely be fruitful in the learning process (Garrison, Anderson, \& Archer, 2000; Garrison \& Cleveland-Innes, 2005). Thoughtful contributions are key to stimulating an active online discussion in which students benefit intellectually.

\section{USING TECHNE TO ESTABLISH AN ACTIVE DISCUSSION FORUM}

One way to establish an active learning forum is "techne." "Techne" is a Greek work for "art" or "craft." It is the root of the word "technique," signifying that techniques used in online discussion forums should be creative, artful, and intentional. The concept of "techne" when applied to online learning, advocates for thoughtful strategies that instructors can use in the discussion forum to enhance active learning. Facilitating a fruitful discussion forum is an art thoughtfully honed over time. The facilitator, then, assumes the role of crafter or artist. Each discussion, as well as the questions and discussions found within, is unique and created from an organic process not very different than creating a musical composition. Each note builds on the last, and every instrument comes together with a unique contribution - all dependent upon the activity of each player. The conductor or instructor guides the discussion, unobtrusively, yet expertly, until the performance is complete.

\section{FOUNDATIONS OF ACTIVE LEARNING IN DISCUSSION FORUMS}

Knowledge regarding distance education suggests that productive discussions are crucial to learning in an asynchronous online environment (Gao, Wang, \& Sun, 2009; Gao, Zhang, \& Franklin, 2013). Online discussions effectively take the place of face-to-face classroom discussion. It is essential for participants to embrace four dispositions to build a productive online discussion: (1) discuss to comprehend, (2) discuss to critique, (3) discuss to construct knowledge, and (4) discuss to share (Gao, Wang, \& Sun, 2009). This model provides a comprehensive, systematic framework to understanding how active learning takes place in discussion forums (Gao, Wang, \& Sun, 2009). In concert, these techne set the foundation for effective learning in the discussion forum. Gao, Zhang, and Franklin (2013) expounded upon the 2009 framework, which the authors have named the "Four Cs":

1. Comprehension: Productive discussions are filled with questioning, interpreting, elaborating, or relating information to prior knowledge. According to cognitive psychologists, information is more likely to be understood or retained when focused on these cognitive activities (Gao, Zhang, \& Franklin, 2013). 
Instructors must focus on enhancing student comprehension through intentional questioning and information-relating techniques.

2. Critiquing: Conflicting perspectives of students should be carefully developed and examined in any productive discussion. Knowledge acquisition originates in cognitive conflicts stemming from social interactions. These conflicts not only occur between students but also between an individual's existing knowledge and new information encountered in discussions with other students. Learning takes place when students reexamine their original positions on an issue and explore new resolutions (Gao, Zhang, \& Franklin, 2013). In the discussion forum, instructors must artfully encourage students to examine deeply held and burgeoning beliefs, as well as the origins of those beliefs.

3. Constructing knowledge: Gao, Zhang, and Franklin (2013) suggested that a productive online discussion should offer opportunities for interaction and collaboration with classmates. From a social constructivist perspective, individuals do not learn in isolation. It is only through interaction that a richer understanding of the topic will take place. Instructors must make efforts to ask questions or pose scenarios in the forums that build community and offer opportunities for collaboration.

4. Communal activity: Productive learning occurs when students are part of a larger, active community (Lave \& Wenger, 1991). A community of learners, which represents the ideal discussion forum environment, is one in which students embrace a sense of belonging, support each other, develop shared values, and enjoy their shared identity. Cognitively, communal efforts allow students to leverage knowledge (Gao, Zhang, \& Franklin, 2013). Consider the adage "two heads are better than one." The discussion board becomes a Socratic form of learning and inquiry between student and instructor as well as between student and student, in which their active participation and defense of their ideas strengthens the learning process for everyone involved.

\section{ACTIVE LEARNING TECHNE MODEL FOR DISCUSSION FORUMS}

Gao, Wang, and Sun (2009) and Gao, Zhang, and Franklin (2013) offered foundational knowledge of active learning in the online discussion forum. The authors of this article seek to add to this foundation by offering a conceptual model that delineates the stages of the recursive process involved in developing and implementing techne into discussion forums. Using techne to enhance learning in the discussion forum is a process that requires careful consideration and time, as well as a willingness to revisit ideas to improve the experience for each student. The process continually shifts, not only between students but also between courses. Figure 1 below depicts a proposed conceptual model for active learning techne in the online discussion forum.

The conceptual model illustrates an active process in which the instructor is receptive to examining not only the success of the techne within the online discussion forum but also a process in which the instructor actively examines the forum in search of new techne that can be implemented or existing techne that may be improved in future course offerings. Instructor observation of interactions in the discussion threads and student feedback can assist in identifying areas of opportunity within the discussion forums.

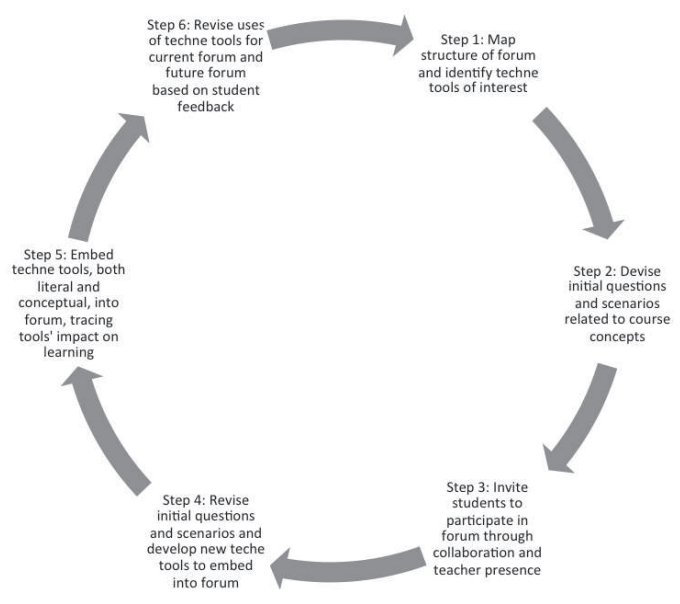

Figure 1. Conceptual model of active learning techne in the online discussion forum. 


\section{ACTIVE LEARNING TECHNE STRATEGIES FOR DISCUSSION FORUMS}

The theoretical framework for active learning in online environments, outlined by Gao, Sun, and Wang (2009) and Gao, Zhang, and Franklin (2013), provides a foundation from which to enact questioning and commenting techniques in the discussion forum. The conceptual model above presented by the authors delivers a series of recursive procedural steps to ensure active learning techne are integrated into the discussion forum. Specific techne tools include applications, programs, and strategies that will help online discussions become as interactive as possible. The authors proffer the following specific techne tools to demonstrate practical methods to design and guide the online discussion forum:

1. Verbally reach all students in the forum: In conversation, it is important to acknowledge all participants, even those who are not speaking, by making eye contact, nodding, and responding as needed. Although it is impossible to deliver non-verbal cues in an asynchronous discussion forum, it is possible to build teacher presence and simultaneously validate students' presence. All students contribute to discussions in some form during a course; it is the instructor's responsibility to acknowledge these efforts. Recognition can include a congratulatory post, a note of thanks or a question or scenario designed to further thinking. Instructors should strive to distribute these "extra touches" evenly among students so that all students are acknowledged and their contributions appreciated. These connections take mere minutes, but can make a significant difference in the online experience for students. Reaching out to students encourages them to participate and, ultimately, become an active learner.

2. Discern what each student needs: What students say (and do not say) in the forum communicates their comfort level in the course. A student that actively participates in the forums may need the instructor to elevate thinking by challenging perceptions and impressions. For instance, an instructor can ask an engaging question that addresses course content and reaches the highest stratum of Bloom's Taxonomy, in- cluding synthesis and evaluation (Bloom, 1956). Such questions might include, "How would you feel if...," "Judge the value of...," "Imagine what would happen if...," or "Can you develop a proposal to..." A student that expresses confusion about the content in the forums may benefit from formative assessment or a Classroom Assessment Technique, such as the Muddiest Point exercise (Angelo \& Cross, 1993), to help the instructor gauge the point of confusion and to reveal gaps to the student in current knowledge. In short, give students what they need. Identifying and addressing students' unique needs is a technical, challenging feat, but it is necessary to enhance active learning in the online discussion forum.

3. Be open to the possibilities: Discussion forums are not one size fits all; postings are not either. It is possible to hinder students' active learning when credit is only awarded to posts that are lengthy, particularly at the undergraduate level. Students may occasionally opt to take a brief turn in the conversation. Consider the value of these posts as long as they are substantive, of merit, and add to the discussion. While some instructors may be held to established grading rubrics or expectations, which could hinder grading flexibility, typically some degree of freedom is given to online instructors when awarding points to participation and discussion question responses. As a result of the Zone of Proximal Development and scaffolding, two theories which suggest that support, guidance, and patience can result in students' ability to find success with more complex tasks, this conscious instructional move entices students to participate in more advanced questions and activities in the forum (Wood \& Middleton, 1975; Vygotsky, 1978).

4. Know when to lead and when to be led: There are occasions when instructors need to guide the discussion and times when instructors should allow students to carry the weight. One common pitfall instructors make in the online classroom is to attempt to control every conversation. At times, 
students may need to take charge to learn the material. For example, if an instructor poses a challenging question to the class, he or she does not need to respond to every response with another challenging question if students are actively responding to the original post. Allowing an ebb and flow to the discussion forum encourages student autonomy and thus active learning.

This list represents four techne that can be embedded into the classroom by online instructors to establish an active learning environment. Other techne beyond the list above of four strategies include offering technical support and constructive feedback, establishing fair and ethical interactions between stakeholders, and setting clear expectations to improve understanding of course content (Gerlock \& McBride, 2013; Mokoena, 2013).

\section{ACTIVE LEARNING TECHNE TOOLS FOR DISCUSSION FORUMS}

One might wonder how asynchronous discussions might be truly "active" in the Deweyan sense. However, the online instructor must take a very active role in mindfully guiding the discussion and gently steering it, as well as knowing when it should be steered by its participants, to a satisfying end. In this case, both the facilitation and the resulting student activity may be an example of "active learning." Although conversations in the online discussion forum take place at different ti194mes, learning can occur through carefully selected techne that invite active conversation, even if not held in real time.

Admittedly, the prospect of adding a synchronous layer to otherwise asynchronous online discussions is intriguing. Many online learning platforms are able to accommodate the addition of programs such as Elluminate, Go to Meeting, and Google Hangout, which can host online synchronous discussions. For instance, an instructor could invite students to discuss a particular module topic on a single day and time using a synchronous tool, recording the discussion for students who could not attend. The instructor could devise a series of well-crafted questions to pose to students to ensure module objectives remain at the fore of the conversation. A techne artist weaves key terminology and concepts, redirects conversations that may be best served in a different venue, and ensures appropri- ate levels of conversation from students. Further, these tools provide an opportunity for students to engage in real time conversations, which are not built into most learning management systems. The possibility of enhancing active asynchronous environments with scheduled synchronous discussions can deliver an active learning experience.

\section{THE FUTURE OF TECHNE IN THE ONLINE DISCUSSION FORUM}

A unique and fruitful discussion is not "created" before students enter the classroom. On the contrary, it is crafted through a process of techne that will produce new content, questions, highlights, and takeaways each time the class is taught. When students are invited in helpful, productive ways to actively create knowledge through interactions with peers (Dewey, 1916; Freire, 1970; Vygotsky, 1978), learning takes place. Certainly, productive discussion can come from a detached approach to the forums. The dynamics of any classroom, with its unique blend of students, can inherently elicit learning. Haphazard or hands-off methods may still initiate fruitful commentary from students. Nevertheless, artful, well-crafted discussions that use techne are powerful learning opportunities for both teacher and student. If the instructor is a composer, then the students' words are his or her music, each note reverberating against the others to create a symphony of critical thinking. Whether the instructor uses techne to organize the forum for maximum productivity or to develop questionposing strategies that elicit thoughtful student responses, all of these avenues produce learning opportunities. The more imagined and imaginative a discussion forum becomes the more learning can take place.

Comprehension, critical thinking, construction of new knowledge, along with academic discourse and socialization, are natural byproducts of techne focused on active learning (Gao, Sun, \& Wang, 2009; Gao, Zhang, \& Franklin, 2013). Humans are innately curious beings (Dewey, 1916). Instructors must seek to provide opportunities for students to be more than receptors of information. The online discussion forum is a locus for active learning through the use of techne. When instructors focus on the techne of enriching online discussion among a community of learners, the resulting discussion will resemble a virtual masterpiece. 


\section{References}

Allen, I. E., \& Seaman, J. (2013). Changing course: Ten years of tracking online education in the United States. Retrieved from http://www.onlinelearningsurvey.com/reports/changingcourse. pdf

Angelo, T. A., \& Cross, K. P. (1993). Classroom assessment techniques: A handbook for college teachers. San Francisco, CA: Jossey-Bass.

Bliuc, A., Ellis, R., Goodyear, P. \& Piggott, L. (2009). Learning through face-to-face and online discussions: Associations between students' conceptions, approaches and academic performance in political science. British Journal of Educational Technology, 41(3), 512-524.

Bloom, B. S. (1956). Taxonomy of educational objectives, Handbook I: The cognitive domain. New York: David McKay Co Inc.

Bradley, M. E., Thom, L. R., Hayes, J., \& Hay, C. (2008). Ask and you will receive: how question type influences quantity and quality of online discussions. British Journal of Educational Technology, 39(5), 888-900. doi:10.1111/j.14678535.2007.00804.x

Dewey, J. (1916). Democracy and education: An introduction to the philosophy of education. New York: Macmillan.

Freire, P. (1970). Pedagogy of the oppressed. New York: Continuum.

Gao, F., Wang, C. X., Sun, Y. (2009). A new model of online discussion and its implication for research and instruction. The Journal of Educational Technology Development and Exchange. 2(1), 65-78.

Gao, F., Zhang, T., \& Franklin, T. (2013). Designing asynchronous online discussion environments: Recent progress and possible future directions. British Journal of Educational Technology, 44(3), 469-483.

Garrison, D. R., Anderson, T., \& Archer, W. (2000). Critical inquiry in a text-based environment: Computer conferencing in higher education. The Internet and Higher Education, 2(2-3), 87-105].

Garrison, D. R., \& Cleveland-Innes, M. (2005). Facilitating cognitive presence in online learning: Interaction is not enough. The American Journal of Distance Education, 19(3), 133-148.

Gerlock, J. A., \& McBride, D. L. (2013). Managing online discussion forums: Building community by avoiding the drama triangle. College Teaching, 61(1), 23-29. doi:10.1080/87567555.2012.7 13042
Hawkes, M. (2006). Linguistic discourse variables as indicators of reflective online interaction. American Journal of Distance Education, 20(4), 231-244.

Kayler, M. \& Weller, K. (2007). Pedagogy, self-assessment, and online discussion groups. Journal of Educational Technology \& Society, 10(1), 136-147.

Lave, J. \& Wenger, E. (1991). Situated learning: Legitimate peripheral participation. Cambridge: Cambridge Press.

Mitchem, K., Fitzgerald, G., Hollingsead, C., Koury, K., Miller, K., \& Tsai, H. (2008). Enhancing case-based learning in teacher education through online discussions: Structure and facilitation. Journal of Interactive Learning Research, 19(2), 331-349.

Mokoena, S. (2013). Engagement with and participation in online discussion forums. Turkish Online Journal of Educational Technology, 12(2), 97-105.

Morris, K.V., Finnegan, C. \& Sz-Shyan, W. (2005). Tracking student behavior, persistence, and achievement in online courses. Internet and Higher Education, 8(3), 221-231.

Palenque, S., \& DeCosta, M. (2014, August 11). The art and science of a successful online discussion. In Faculty Focus. Retrieved from http://www.facultyfocus.com/articles/onlineeducation/art-science-successful-online-discussions/

Ragan, L. C. (n.d.). 10 principles of effective online teaching: Best practices in distance education. In Faculty Focus. Retrieved from http://www.facultyfocus.com/free-reports/principles-of-effective-online-teaching-best-practices-in-distance-education/.

Vygotsky, L. S. (1978). Mind and society: The development of higher psychological processes. Cambridge, MA: Harvard University Press.

Wood, D., \& Middleton, D. (1975). A study of assisted problemsolving. British Journal of Psychology, 66(2), 181-191. 


\section{Author Biography}

Stephanie Maher Palenque is an Assistant Professor, researcher, and writer in the College of Humanities and Social Sciences at Grand Canyon University. Her scholarship focuses on writing education, online instruction, and instructor facilitation in online discussions. Palenque was the corecipient of a scholarly engagement grant in which she studied plagiarism from a faculty perspective in the online modality. She has presented her work in these areas at professional conferences and as a contributor to academic and peer-reviewed journals. She is currently working toward her $\mathrm{PhD}$ in Psychology with an emphasis in Cognition and Instruction.

Meredith DeCosta, $\mathrm{PhD}$, is a faculty manager, instructor, researcher, and writer at Grand Canyon University. Her work focuses on Web 2.0 literacies, writing education, and educational equity in urban, multicultural contexts. She has written several peer-reviewed journal articles and book chapters and has a co-authored book with Columbia University's Teachers College Press titled Real World Writing for Secondary Students. Meredith's most recent award for her work is the Grand Canyon University Leadership in Research and Scholarly Activity Award. 